r. During descent of the diaphragm, the posterior portions of the heart and the venæ cavæ descend more than the anterior portion of the base, while the anterior aspects of the apex move forward and as a result often slightly upward. The right and left borders of the ventricle move toward the right.

2. The movement of the heart to the right does not occur after severing the left phrenic nerves nor upon stimulating the right phrenic nerve. It is, therefore, due to a traction of the left sheath of the pericardium.

3. A descent of the base of the ventricles, the auricles and venæ cavæ occurs after the entire pericardium is severed from the diaphragm. Direct experiments show that this is due in part to a traction upon the inferior vena cava making it larger and narrower.

4. The descent of the base of the heart persists after the vena cava is clamped and divided. This results from a traction upon the ligamentum pulmonale (a double fold continuous with the pleura pulmonalis, and passing downward from the root of the lung to its vertebral and diaphragmatic attachments) which causes the roots of the lungs, the pulmonary vessels and through these the base of the heart to move downwards.

\title{
$66(883)$
}

Experiments dealing with the relation of the sinus node to the effects of stimulation of the vagus nerves.

\section{By Alfred E. CohN.}

[From the Hospital of the Rockefeller Institute for Medical Research, New York.]

Experiments by a number of investigators on the sino-auricular node have warranted the conclusion that this structure is responsible for stimulus production and the maintenance of the rate of the heart. Flack thought that this node formed a station in the pathway, both of the vagus and of the accelerator nerves, and that through its agency they exercised their influence on the heart. He attempted to show that exclusion of the node from function consequently interrupted impulses passing over the nerves. 
It is the purpose of this paper to report that a large number of experiments have been performed on dogs to determine the relation of the vagus nerves to the sinus node. The experiments were performed under ether; a small opening in the chest was made by resecting one or two ribs, and both vagus nerves were dissected, cut and laid on shield electrodes. Records were taken electrocardiographically. The results of stimulation of both vagus nerves were first registered. Then the sinus node was carefully clamped off with a suitable T-shaped clamp, all the tissue surrounding the node being crushed. Stimulation of both vagus nerves was repeated and records were obtained.

In the greater number of experiments, it could be shown that stimulation of the vagus nerves after clamping the node was effectual in producing effects on the rate and on the rhythm of the heart in a way similar to that seen before the clamp was placed. In a number of cases the effect of stimulation was more profound after than before the clamping. The conclusion is therefore warranted that the sinus node does not represent a simple relay in the course of the vagus nerves.

These experiments will be published in detail later, and the histological examinations of the areas at which the clamp was applied will be reported.

\section{$67(834)$}

The energy requirement of the new boin.

By H. C. BaILeY and J. R. MURLIN.

[From the Physiological Laboratory of Cornell University and the Maternity Wards of Bellevue Hospital.]

To find whether it would be desirable from a physiological standpoint to furnish some artificial food together with the colostrum during the first three days of life, the energy requirement of the newborn was ascertained by means of a respiration incubator.

Series of cases from the wards of Bellevue Hospital show that the initial weight loss averages over $250 \mathrm{gm}$. and that this loss is increased by lengthening the interval of feedings and lessened by 